\title{
Fascismo e profissionalização da contrarrevolução no Brasil
}

\author{
Thays Karolline dos Santos Fidelis ${ }^{1}$ \\ https://orcid.org/0000-0002-8713-0451
}

\author{
Raphael Lana Seabra ${ }^{2}$ \\ https://orcid.org/0000-0003-1203-8965
}

${ }^{1}$ Universidade Federal de Alagoas, Faculdade de Serviço Social, Programa de Pós-Graduação em Serviço Social, Maceió, AL, Brasil

${ }^{2}$ Universidade de Brasília, Departamento de Estudos Latino-Americanos, Programa de Pós-Graduação em Ciências

Sociais, Brasília, DF, Brasil

\section{Fascismo e profissionalização da contrarrevolução no Brasil}

Resumo: Neste artigo objetivamos entender o processo de fascistização hodierna no Brasil a partir do entendimento de Leandro Konder sobre o fascismo clássico e do debate levantado por Ruy Mauro Marini e Theotônio dos Santos sobre a tendência autoritária que os países de capitalismo dependente apresentam. Partindo disso, buscamos analisar o processo de radicalização da direita no Brasil a partir de 2013 e como isso resultou na eleição do atual governo federal. Concluímos que o processo de fascistização hodierna no Brasil não vislumbra a instauração de um Estado fascista e sim de um Estado democrático moderado pela militarização da política.

Palavras-chave: Fascismo. Brasil. Contrarrevolução. Democracia.

\section{Fascism and counter-revolution's professionalization in Brazil}

Abstract: In this work we intent to understand the current process fascistization in Brazil based on Leandro Konder's understanding of classical fascism and the debate raised by Ruy Mauro Marini and Theotônio dos Santos about authoritarian tendency those dependent capitalism countries present. From this, we seek to analyze the process of right-wing radicalization in Brazil since 2013 and how this resulted in the election of the current federal government. We conclude that the process of fascistization in Brazil today does not envision the establishiment of a Fascist State, but a Democratic State moderated by militarization of the politics.

Keywords: Fascism. Brazil. Counter-revolution. Democracy. 


\section{Introdução}

A conjuntura política e social mundial e o caso brasileiro em particular têm feito com que a temática do fascismo reapareça como uma definição incontornável para alguns partidos, movimentos e mesmo importantes lideranças políticas ao redor do mundo, tanto no centro como na periferia do capitalismo. No centro, a política dá mostra de tendências fascistas na França com a Frente Nacional de Marine Le Pen, na Itália com a Liga do Norte do ex-vice-premiê Matteo Salvini e nos Estados Unidos sob a presidência do republicano Donald Trump. A periferia infelizmente não fica muito atrás com políticos como o ex-presidente Maurício Macri na Argentina, como o ex-presidente Álvaro Uribe na Colômbia, o presidente Recep Tayyip Erdoğan na Turquia, o presidente Rodrigo Duterte nas Filipinas, e o presidente Jair Bolsonaro no Brasil. Até o islamismo fundamentalista vem sendo enquadrado na categoria e, mais recentemente, o Estado Islâmico do Iraque e da Síria representaria um novo tipo de fascismo.

Apesar do fascismo ser um dos fenômenos políticos mais significativos do século XX e com reflexo no século XXI, a imensa literatura acerca dele, de fontes liberais ou até de fontes socialistas, acabam impedindo que ele seja entendido efetivamente e, por conseguinte, enfraquecem os movimentos contrários às tendências fascistas. Mesmo assim, a terminologia fascista aparece de maneira recorrente nas diversas vertentes da luta política sem a rigidez científica do termo, sendo utilizada para agitação de maneira esvaziada — perdendo as vantagens políticas que esse fenômeno político poderia dar às análises da realidade.

$\mathrm{O}$ conceito de fascismo é comumente relacionado aos movimentos reacionários e conservadores ou é reduzido aos conceitos de ditadura, de bonapartismo ou de autoritarismo, porém nem todas as formações sociopolíticas que recorreram/recorrem sistematicamente ao terror contrarrevolucionário podem ser enquadradas como fascistas. Aparece para nós, então, uma questão: o que é o fascismo?

Para nós é imprescindível entender esse fenômeno em sua maneira clássica para destacar as particularidades das formas terroristas que o Estado no capitalismo dependente assumiu e continua precisando assumir para garantir a reprodução do capital. A referência ao fascismo como categoria para compreensão da natureza da dominação e exploração na América Latina não é inteiramente nova, foi algo bastante comum para entender os golpes empresariais-militares que ocorreram na região nos anos 1960-1970. Tanto o fascismo como esses golpes na América Latina são formas de contrarrevolução (assim como o foi o bonapartismo a seu tempo), mas isso não pode fazer com que a referência ao fascismo subordine a particularidade da contrarrevolução e do Estado na América Latina à realidade europeia dos anos 1920-1930 (BORÓN, 2003; MARINI, 2008) - se tal análise foi válida para a conjuntura dos anos 1970, continua válida até o momento ${ }^{1}$. Assim, é fundamental resgatar o conceito de fascismo do seu mal-uso (e não simplesmente rejeitá-lo devido à leitura equivocada), tendo claro que embora a maioria das sociedades modernas tenha gerado movimentos fascistas ao longo do século XX e início do século XXI, pouquíssimos desses movimentos chegaram a formar um Estado fascista de fato (PAXTON, 2008).

Neste artigo buscamos apresentar brevemente uma sucinta definição do fascismo histórico para então lançar luz sobre as possibilidades ou não de que tal fenômeno se reproduza atualmente num país periférico, tal como o Brasil. Para isso utilizaremos a síntese de Leandro Konder acerca do fascismo clássico e o debate levantado por Ruy Mauro Marini e Theotônio dos Santos sobre a particularidade brasileira. De posse dessas discussões, apresentaremos uma análise do processo de fascistização brasileiro e de como a temática do fascismo nos é cara para os possíveis rumos do país.

\section{Fascismo histórico}

A definição do fascismo não é uma definição fácil, pois muitas vezes é definido apenas como movimento político de negação. Seria, portanto, antiliberal, antidemocrático, antissemita, anticomunista, anti-iluminista, antimoderno. Seria, assim, um movimento incapaz de criar uma forma original e coerente de ideologia, o que o torna não apenas vago, mas faz com que possa existir em todo e qualquer lugar, basta dobrá-lo à realidade. Do mesmo modo, a categoria de neofascismo também não se enquadra bem na análise desse processo, porque ele é simplesmente uma tentativa de resgatar, perpetuar e colocar em prática o velho fascismo, o fascismo histórico (TRAVERSO, 2019). 
Para começarmos a entender o fascismo é importante entender o que é a direita, pois, segundo Konder (2009, p. 27), "a direita é o gênero de que o fascismo é uma espécie". A direita é o conjunto de "forças sociais empenhadas em conservar determinados privilégios, isto é, em conservar um determinado sistema socioeconômico que garante o estatuto de propriedade de que tais forças são beneficiárias" (KONDER, 2009, p. 27). Porém, não podemos identificar o conservadorismo intrínseco à direita às formas políticas fascistas de imediato, pois além do conservadorismo outra característica compõe essa direita: o pragmatismo. Este exige dos conservadores eficácia política para garantir a conservação de determinado sistema socioeconômico — para garantir tal eficácia são necessárias "iniciativas concretas, manobras, concessões, acordos, golpes de audácia, formas de arregimentação das forças disponíveis que transcendem da mera atitude doutrinária" (KONDER, 2009 , p. 28 , grifo do autor).

O pragmatismo utiliza-se de uma relativização absoluta que permite o uso de conceitos desligados de suas raízes e isso é essencial para o fascismo, pois este se beneficiaria da mais extrema flexibilidade ideológica ao passo que determinaria uma espécie de princípio sagrado, de mito. Tanto para Mussolini como para Hitler esse mito era a pátria. Eles apresentam a pátria como uma unidade idealizada, sem seus diversos conflitos, apresentando-a como uma nação proletária e determinando os inimigos: os antinação e as nações vencedoras da guerra que haviam proletarizado seus respectivos países. Em ambos os países, Itália e Alemanha, "os trabalhadores eram convidados a ver seus compatriotas capitalistas não como beneficiários de um sistema social baseado na exploração interna, mas sim de colegas proletarizados (ou em vias de proletarização), vítimas de um sistema de exploração internacional" (KONDER, 2009, p. 37, grifo do autor). O nacionalismo fascista (ou falso nacionalismo) assume posturas demagógicas para manipulação das massas, criando uma noção de povo tão mítica quanto a de nação. Nesse sentido, Konder diferencia o nacionalismo verdadeiro do nacionalismo fascista.

O nacionalismo que exprime os sentimentos de um povo explorado pelo capital estrangeiro ou que exprime a revolta de um povo contra imposições de outra nação é um nacionalismo essencialmente defensivo: seus valores podem levá-lo a hostilizar circunstancialmente os estrangeiros exploradores, mas ele não se afirma em contraposição à humanidade em geral e não nega os valores das outras nações. A valorização fascista da nação, ao contrário, exatamente porque é inevitavelmente retórica, precisa ser agressiva, precisa recorrer a uma ênfase feroz para disfarçar o seu vazio e tende a menoscabar os valores das outras nações e da humanidade em geral² (KONDER, 2009, p. 40, grifo do autor).

Não podemos, no entanto, entender romanticamente essa noção de nacionalismo verdadeiro e identificá-lo imediatamente aos países de capitalismo periférico. Nestes o nacionalismo pode, assim como o nacionalismo fascista, valorizar a nação apenas de maneira retórica, negar seus próprios valores e se submeter à lógica de reprodução do capital mundializado, processo no qual os países-nação servem apenas como pontes diretas para o capital estrangeiro determinar e condicionar a reprodução do capital à nível nacional, submetendo os países dependentes aos ditames da reprodução ampliada do capital.

Mesmo o fascismo colocando o mito da nação acima dos valores do gênero humano, esse fenômeno político conseguiu adeptos em todas as classes sociais. E isso só foi possível porque tanto no plano econômico, social e político, como no plano cultural a direita havia preparado o terreno para a chegada do fascismo. Eis algumas medidas dessa preparação: "bombardeio constante e prolongado, que destruía não só os princípios do liberalismo como, sobretudo, as convicções democráticas e a confiança nas massas populares" (KONDER, 2009, p. 43); menosprezo, nos meios intelectuais, das classes populares, subestimando sua capacidade política e desagregação da vida social (tendência do capitalismo) e a "solução mágica" para a exigência social de integração da vida comunitária - em alguns casos o mito da nação apresenta-se como a solução, em outros acrescenta-se o mito da família para compor a solução de satisfazer as exigências de vida comunitária.

Essa exigência de vida comunitária foi a isca para recrutar adeptos em todas as classes, afinal a maioria queria fazer parte da raça ariana, no caso da Alemanha, ou fazer parte dos herdeiros de César, no caso da Itália. Desse modo, a substituição da autêntica comunidade humana pelo mito da nação "é uma característica essencial do fascismo e se manifesta em todos os movimentos desse tipo, independente dos países em que se realizam e independentemente das formas particulares que assumem" (KONDER, 2009 p. 45, grifo do autor).

Robert Paxton (2007) define de maneira sucinta o fascismo: 


\begin{abstract}
O fascismo tem que ser definido como uma forma de comportamento político marcada por uma preocupação obsessiva com a decadência e a humilhação da comunidade, vista como vítima, e por cultos compensatórios da unidade, da energia e da pureza, nas quais um partido de base popular formado por militantes nacionalistas engajados, operando em cooperação desconfortável, mas eficaz com as elites tradicionais, repudia as liberdades democráticas e passa a perseguir objetivos de limpeza étnica e expansão externa por meio de uma violência redentora e sem estar submetido a restrições éticas ou legais de qualquer natureza" (PAXTON, 2007, p. 358).
\end{abstract}

Além dessa definição, o referido autor elenca uma série de paixões mobilizadoras do fascismo que entendemos encontrar terreno fértil na sociedade brasileira. Essas paixões seriam: a) percepção de que atravessamos uma crise de enormes proporções para a qual as soluções no interior da democracia liberal parecem insuficientes; b) a construção de grupos de dentro com deveres e direitos superiores aos outros de fora que não são passíveis de reintegração ou ressocialização; c) a crença de que estes de dentro (os cidadãos de bem) são vítimas da indolência, da malandragem, da corrupção, da degeneração de valores e reversão das hierarquias sociais tradicionais; d) esse pavor da decadência do cidadão de bem exige uma comunidade mais pura, se possível pela violência; e) a necessidade da autoridade (sempre do sexo masculino), culminando no chefe nacional, único capaz de encarnar o destino histórico da sociedade; f) a superioridade do instinto do líder sobre a razão abstrata e universal; g) a estetização da violência e eficiência da vontade, sempre que voltadas para o êxito do cidadão de bem; h) o direito do cidadão de bem dominar e se impor sobre os demais, sem restrições relativas a qualquer lei constitucional, divina ou preceito moral, onde o que interessa é vencer no interior de uma luta darwiniana.

Todas essas paixões parecem sugerir a existência de um movimento fascista significativamente influente, cujas ideias atravessam a sociedade brasileira de forma incisiva. Mas até que ponto o que vemos é efetivamente fascismo? Em que medida este uso indiscriminado do conceito nos ajuda de fato a compreender fenômenos qualitativamente diferentes entre si? Seriam as afirmações de bandido bom é bandido morto, o manifesto ódio às diversidades raciais e de gênero e até mesmo os pedidos de intervenção militar constitucional já (sic) fortes indicativos de uma fascistização da sociedade? Entendemos, então, que a conjuntura brasileira nos exige discutir e debruçar sobre os possíveis elementos fascistas presentes no cenário político do momento.

\title{
Diferenças entre o fascismo histórico e o possível fascismo no Brasil
}

Não há espaço para estabelecer uma longa análise comparada entre o fascismo histórico e as possibilidades do fascismo no Brasil, mas indicaremos algumas diferenças básicas, alguns limites das análises que afirmam que vivemos atualmente num movimento político fascista ou até um Estado fascista.

Um primeiro limite é que as avaliações focam de forma superficial na personalidade de Bolsonaro: no estilo de pensamento e forma de agir muito autoritária; por ser um homem de ação e não um homem de reflexão; pela obsessão na ditadura civil-militar e na militarização da vida cotidiana; pelas inúmeras manifestações de sexismo ofensivo, de racismo e de xenofobia abertas; pela reafirmação da virilidade vulgar e grosseira; por ser marcadamente anticomunista, mas de forma muito vaga; pelo posicionamento contrário às políticas de cotas, de demarcação de terras indígenas e quilombolas, entre outras coisas. Individualmente ele pode ser fascista, mas o fascismo como movimento político demanda mais do que a vontade do indivíduo, exige um movimento político complexo.

Um segundo limite ou diferença é que o governo Bolsonaro não tem programa político claro, não tem projeto de sociedade. O fascismo histórico no contexto dos anos 1920-1940, ainda que fosse ideologicamente bastante eclético, se apresentava como alternativa totalizante àquilo que se considerava como ordem liberal decadente (TRAVERSO, 2019). Bolsonaro não promove nenhum projeto alternativo de sociedade, o lema Brasil acima de tudo, Deus acima de todos é algo vazio, que não diz absolutamente nada. Não há nenhuma indicação de transformação do programa econômico neoliberal, simplesmente trata-se de continuar seu aprofundamento e liquidar a parca soberania nacional. Inclusive sequer a pauta moral e punitivista é consensual entre os membros de sua peculiar base parlamentar.

Uma terceira diferença é que o fascismo histórico surgiu num momento de forte intervencionismo estatal na economia, fato que valia tanto para o capitalismo nos Estados Unidos como para o socialismo 
soviético e o próprio fascismo. Era o momento da produção fordista-taylorista, de produção e consumo de massa (TRAVERSO, 2019), era o momento de implementação da fase monopólica do capitalismo que exigia uma ampliação das funções do Estado para atender a esse processo de monopolização. Bolsonaro desponta na época do neoliberalismo, do capitalismo financeiro, do individualismo competitivo, da precariedade do trabalho, da destruição de direitos sociais, do isolamento cada vez maior do indivíduo em relação ao conjunto da sociedade - num sentido contrário ao fascismo histórico que unia e buscava garantir as condições de vida dos que pertenciam à nação fascista.

A quarta dificuldade é a ausência de movimento de massas. O Governo Bolsonaro não mobiliza a massa de forma constante, não existe como no fascismo histórico uma experiência estética e sensual da política. Essa massa que o segue é totalmente atomizada, ela é mobilizada por redes sociais, de forma efêmera, composta por consumidores empobrecidos, desesperados pelo desemprego, vítimas da violência urbana cotidiana, e que não estão organizados. O caso brasileiro é mais complexo, porque no capitalismo dependente o povo sempre tem de estar fora da cena política, a massa é limitada em sua participação política, ela é mobilizada sempre de modo pontual. Por ser uma sociedade baseada na superexploração do trabalho as contradições vão se aprofundando, os níveis de empobrecimento são continuamente ampliados; existe uma forma de relação capital-trabalho que restringe continuamente a dimensão da ordem social competitiva. No curto prazo, esse ressentimento que realmente existe, de fato, contribui para certa qualidade de mobilização instantânea, mas as condições objetivas não permitem que essa mobilização seja constante, existe uma contradição entre o discurso do bolsonarismo e a prática concreta da governança neoliberal; um discurso moralista, punitivista e pós-ideológico, mas a prática concreta do governo é de liquidar o patrimônio nacional, de destruição de direitos sociais, de redução dos níveis de emprego, da capacidade produtiva, de alinhamento automático e subserviente aos Estados Unidos. Não há e não haverá distribuição de riqueza, no médio prazo esses indivíduos não terão o retorno equivalente ao apoio que está sendo dado ao governo.

A quinta distinção com o fascismo histórico é que a presença maciça de militares no governo e a nostalgia de Bolsonaro dos tempos da ditadura civil-militar seriam indícios de fascistização do Estado. Apesar desses elementos aproximarem o governo da concepção militarista do fascismo, da sua tendência expansionista e de solução pela força, temos, na América Latina uma particularidade na relação entre os governos e as Forças Armadas. Estas sempre alimentaram no imaginário popular a crença de que seriam os guardiões da nação, da moralidade e do nacionalismo, sendo melhores do que qualquer partido ou governo civil. Elas seriam o bastião de defesa dos valores ocidentais. Com isso queremos dizer que as manifestações saudosas da ditadura civilmilitar e os chamados de intervenção militar não representam por si mesmos nenhuma adesão ao fascismo, mas, sim, parte de um imaginário que vê nessa instituição estatal uma força que paira acima de interesses individuais, partidários e mesmo de classe, dotada de ordem suficiente para levar a nação ao progresso — um imaginário presente desde 1882 no Brasil.

Sem esgotar, mas por último, temos uma questão que nos parece muito próxima ao fascismo histórico, mas que na realidade enquadra uma diferença histórica importante em relação a ele: tanto no contexto europeu entre 1910 e 1940 como no contexto latino-americano das últimas quatro décadas, existe uma vivência com a violência cotidiana que brutaliza as relações sociais, que nos leva a nos acostumarmos com os massacres, com os assassinatos, com as detenções arbitrárias, com os desaparecimentos forçados, com os extermínios de indivíduos anônimos - principalmente nas periferias e no campo - nos acostumarmos com a militarização das relações sociais. Porém, o fascismo - e principalmente, o fascismo alemão - era entendido como uma ação total, envolvente e explicativa de toda a vida, incorporando a morte e o irracionalismo, resistindo à transcendência no mundo moderno, sendo assim uma forma de proteção diante do desconhecido (TRAVERSO, 2019). Existia um elemento de força moral. Em nosso caso, dada a ausência de projeto alternativo de sociedade, nos parece que é pura e simplesmente a vivência da barbárie, de uma forma político-estatal específica para atender interesses da acumulação neoliberal.

Essas diferenças que apresentamos nos leva a crer que, diferente de um processo de fascistização, o que vivenciamos é um aprofundamento de características do Estado na periferia do capitalismo. Esse necessita recorrer a diversas formas e estratégias para atender as exigências da reprodução ampliada do capital, tendo por base a doutrina contrarrevolucionária e a superexploração da força de trabalho. Essas bases nos colocam numa conjuntura de barbárie que, apesar de nos remeterem aos horrores do fascismo histórico, representam simplesmente a continuidade do modo de produção capitalista em sua fase imperialista financeira. 


\section{Fascismo ou profissionalização da contrarrevolução?}

Assim como o fascismo histórico representou um processo particular da contrarrevolução burguesa na Europa, o processo contrarrevolucionário latino-americano do século XX

se inicia com um período de desestabilização, durante o qual as forças reacionárias tratam de agrupar em torno de si o conjunto da burguesia e de causar no movimento popular a divisão, a desconfiança nas suas forças e nos seus dirigentes; continua através de um golpe de Estado, levado a cabo pelas Forças Armadas, e se resolve com a instauração de uma ditadura militar. (MARINI, 1978, p. 23, grifo nossos).

Apesar desses três passos, a superexploração da força de trabalho (FIDELIS, 2020) ${ }^{5}$ não permitiu, no século XX, a derrota política do movimento popular (que permanecia aparentemente forte) e por isso foi necessário o uso da força para a tomada do Estado. Ou seja, os movimentos populares fortalecidos com a pequena burguesia proletarizada, com os movimentos do campo e com novos movimentos dos trabalhadores da indústria impossibilitaram a chegada da nova fração hegemônica burguesa ao poder via eleições ${ }^{6}$ (MARINI, 1978). Devido a isso, a fração burguesa hegemônica tentou refazer o bloco no poder para incluir a pequena burguesia e restabelecer suas relações de aliança com ela. Conseguindo isso, o novo bloco no poder, em aliança com as Forças Armadas, conseguiu desestabilizar o campo popular (que seria o vírus causador dos males do organismo são, a sociedade burguesa democrática) e retomar o discurso ideológico de defesa da democracia.

Esse processo inicia com uma negação da democracia como um meio para um fim grandioso que seria o retorno à democracia ${ }^{7}$, sem os males do campo social. Para conseguir tal façanha, a doutrina de contrainsurgência privilegia as Forças Armadas como elemento central da sua estratégia, dando a ela a tarefa de solucionar o problema. Como se fala popularmente, matou dois coelhos com uma cajadada só: satisfez a vontade contrarrevolucionária da burguesia e a vontade de poder das Forças Armadas.

Da doutrina de contrainsurgência surge um Estado de contrainsurgência que é um Estado no qual suas estruturas e funcionamento tem coparticipação entre as Forças Armadas e o capital monopólico, tendo esse Estado a forma de uma ditadura militar ou qualquer outra forma. Durante o período de 1964 a 1985 o Estado brasileiro adquiriu a forma de uma ditadura militar, na qual as Forças Armadas assumiram seu controle e poder político. Porém seu conteúdo foi compartilhado entre as Forças Armadas e a burguesia monopólica. Em síntese,

o Estado de contra-insurgência é o Estado corporativo da burguesia monopólica e das Forças Armadas, independente da forma que assuma esse Estado, quer dizer, independente do regime político vigente. Esse dito Estado apresenta similaridades formais com o Estado fascista, assim como com outros tipos de Estado capitalista, mas sua especificidade está em sua peculiar essência corporativa e na estrutura e funcionamento que geram dali. Chamá-lo de fascista não nos faz avançar um passo na compreensão do seu significado (MARINI, 1978, p. 24, grifos do autor).

Nessa forma de Estado deveria haver a institucionalização da participação direta do grande capital na gestão econômica e a subordinação dos poderes do Estado às Forças Armadas, que exerceria um poder moderador além dos três poderes clássicos do Estado (Legislativo, Executivo e Judiciário). Essa definição de estado de quarto poder de Marini nos deixa uma questão: os 21 anos de ditadura empresarial militar que tivemos no Brasil foram uma espécie de fascismo ou uma espécie de democracia?

Santos (1991) afirma que o Estado de exceção com utilização sistemática do terror que tivemos no Brasil de 1964 até 1985 foi uma espécie de fascismo dependente. Para ele, no fascismo latino-americano também há hegemonia do capital monopólico, mas de maneira diferente dos países de capitalismo central e da época dos anos 1910 a 1940. O capital monopolista dos países dependentes passa a se integrar internacionalmente (e se utiliza do Estado para isso) e amplia as etapas de concentração e centralização. E mesmo os países latinos que tinham um certo nível de industrialização não conseguiram/puderam superar as características e a condição de dependência e precisaram recorrer ao fascismo (Estado de exceção com utilização sistemática do terror).

Santos (1991) aponta três formas que o fascismo dependente pode tomar: regime militar com abertura política, regime civil com tutela militar (semelhante ao Estado de quarto poder de Marini) ou regime tipicamente civil com restrições às tendências revolucionárias de esquerda. Todas essas formas, no entanto, limitam a democracia e essa limitação depende da existência de um setor pequeno burguês suficientemente forte para 
garantir um certo equilíbrio da democracia — porém esse setor vem sendo debilitado devido à acumulação capitalista, vem sendo proletarizado, criando um problema de hegemonia política entre as frações da burguesia.

De posse dos apontamentos de Marini e Santos e partindo do entendimento de que o padrão de desenvolvimento econômico dominante na América Latina é de caráter dependente, superexplorador, monopolista, concentrador, excludente e marginalizador, observamos uma tendência à formação de governos autoritários e autocráticos cuja tendência para ofascismo dependente é crescente. Porém, para que o processo de fascistização ${ }^{8}$ tenha êxito é necessária uma base forte em meio a pequena burguesia, uma hegemonia ideológica e a criação de um chefe de Estado carismático. Para Santos (1991) essa tendência só pode ser confirmada a) quando/se houver uma radicalização popular que tenda a dificultar a acumulação do tipo populista ou um enfraquecimento tamanho do campo popular que permita o aprofundamento da superexploração da força de trabalho; b) quando/se houver uma hegemonia no bloco do poder para instaurar esse tipo de regime; e c) quando/se a pequena burguesia se sentir ameaçada pelo radicalismo popular ou pela expansão do campo de direitos que ameace seu status quo. Quando percebemos que essas três condições se apresentam na atual conjuntura, o questionamento inicial retorna: os governos autoritários que temos no mundo, em especial no Brasil, podem ser caracterizados como fascistas?

\section{Considerações finais}

Buscamos colocar em evidência que existe uma relação de continuidade no padrão de dominação militarizado do Estado e das relações sociais nos países dependentes, em especial no Brasil, em razão da própria acumulação capitalista. Desde a instituição da república brasileira, em 1889, o Estado brasileiro é tutelado em certa medida pelas Forças Armadas e é marcado historicamente por uma instabilidade, mas desde a redemocratização do país em 1985 e, mais evidentemente, desde 2016, essa militarização deve ser vista como algo mais do que a pura ocupação do poder estatal pelas Forças Armadas, deve ser vista a partir da adoção e disseminação de práticas que direcionam as políticas e a visão de mundo tanto da estrutura jurídico-política do Estado como dos governos civis. A disseminação pelo conjunto da sociedade das concepções da resposta contrainsurgente é evidência da militarização.

Não há dúvida de que o governo Bolsonaro potencializa a militarização do aparato estatal e das políticas governamentais, porém identificar essa potencialização com o fascismo nos faz perder de vista que todo Estado repousa em última instância sobre seu aparato repressivo, de forma que o terror institucionalizado e, muitas vezes, legalizado - e esse nos parece ser o caso dessa nova regularidade da guerra, através da reedição da contrainsurgência - existe no interior das democracias como ameaça latente sobre os grupos contestatórios. Assim, esbarramos no erro tático resultante da lógica de muitos partidos de esquerda no Brasil, de que "se existe terror há fascismo; se ao contrário a violência de classe opera dentro do 'meio institucional' então há democracia burguesa" (BORÓN, 2003, p. 49).

O sistema capitalista em sua fase imperialista aprofunda as contradições e antagonismos que lhe são próprios, e para mantê-los deve recorrer, repetidamente, ao terror — que serve inclusive como uma alavanca extraeconômica, levando em consideração o setor bélico. Para que as frações burguesas hegemônicas recomponham os mecanismos de acumulação de capital, implementa-se, nessa fase do capitalismo, uma guerra política contra o campo popular (através da retirada de direitos e aniquilação dos movimentos populares) e uma guerra econômica contra os trabalhadores (através do aprofundamento dos mecanismos de exploração e expropriação da riqueza produzida). Vivenciamos, então, no Brasil um período de aprofundamento de um capitalismo de guerra neoliberal e o governo Bolsonaro simplesmente responde aos interesses dos EUA na região. Essas guerras nos aparecem como um processo de fascistização da sociedade brasileira, mas em que setores ou frações de classe o fascismo se apoiaria no Brasil hodierno?

O primeiro setor seria composto pelos grupos mais reacionários da classe média tradicional, ancorada na sensação da perda da distinção frente à ascensão da nova classe média por meio dos programas sociais e que, no pânico de proletarização resultante da crise, reforçam os valores meritocráticos, buscam salvar os bons costumes e a nação que supõem representar.

Um segundo setor, em parte massa de manobra potencial do fascismo, é esta nova classe média, resultante dos anos do novo-desenvolvimentismo, que até pouco vivia na formalidade trabalhista, no sistema 
universitário, nos shoppings centers e aeroportos e repentinamente vê as portas do consumismo se fecharem. Remetida agora à sua insegurança social, vítima dos altos níveis de violência, desenvolvem o imediatismo e o oportunismo que as tornam disponíveis para quem queira mobilizá-las.

O terceiro setor é o latifundiário (agronegócio). Herdeiros históricos legítimos de qualquer ação antipopular, gozam contemporaneamente de alto prestígio como locomotivas do Produto Interno Bruto desde o início dos anos 2000, cuja única forma de enfrentar a sangria de capitais de sua atividade reprimarizante é a expansão contínua da fronteira agrícola e a instrumentalização do papel do Estado a partir de sua expressiva bancada parlamentar.

O quarto setor seria composto por parte da burguesia comercial ou compradora, quer dizer, os proprietários dos grandes grupos atacadistas que se beneficiam diretamente das importações para venda no mercado interno e fazem pesado lobby contra as leis trabalhistas e a previdência social.

O quinto e último setor é composto pela tecnocracia do Estado, incluídos aí os servidores públicos de carreira que ocupam funções e cargos estratégicos no aparelho estatal, mas principalmente aqueles ligados ao poder Judiciário e engajados no ativismo judicial como missão civilizadora e moral e rigidamente embebido nos valores de classe média, com posições intolerantes e punitivas em relação às diferenças e aos que são considerados inferiores.

Esses setores ou frações de classe, diferentemente da época de Mussolini e Hitler, contam com o aprendizado de máquina (ou machine learning) para moldar perfis baseados nos bancos de dados vendidos pelas redes sociais (de e-mail, de comunicação, de interação social etc.) e implementados nelas mesmas. Esse processo de molde pode seguir diferentes vertentes, mas essencialmente é voltada para direcionar o consumo seja de produtos, seja de vertentes ideológicas. No Brasil, conseguimos observar facilmente esse direcionamento do consumo político sob a capa não política desde as manifestações de 2013, quando demandas sociais da classe trabalhadora se transformaram numa saga pelo fim da corrupção, tendo como resultado o golpe que impediu a continuidade do governo de Dilma Rousseff (que não descontinuou a intervenção estatal) e novas condições para a radicalização dos deslocamentos para a direita dos setores conservadores brasileiros. As circunstâncias globais exigem que os fascistas se utilizem do seu pragmatismo padrão para se adaptarem às exigências hodiernas, sem, com isso, perderem a esperança de novos tempos em que possam escancarar sua face fascista - eles depositam suas esperanças na estrutura político-econômica particular latino-americana em que a democracia é sempre um risco e uma impossibilidade dentro do sistema.

Até o presente momento houve uma tentativa de imitação deficiente de fascismo no Brasil, apresentandose retoricamente como que "em vias de consolidação". Parece-nos, no entanto, que sua tarefa primordial era num primeiro momento conter qualquer possibilidade de vitória eleitoral tanto do Partido dos Trabalhadores como de qualquer outra alternativa progressista (sem suspender os direitos democráticos), para num segundo momento criar as condições para a implementação de um programa político privatizador, antipopular e subordinado às imposições do capitalismo central, de modo que seu resultado seja o aprofundamento da superexploração do trabalho como fundamento da dependência, uma espécie de República Oligárquica no Século XXI. Esta, que aparenta por vezes ser um fascismo reativo ou defensivo capaz de se converter num Estado fascista, é, na verdade, a reedição do Estado de contrainsurgência, mantendo a coparticipação entre o capital (agora financeiro, não mais monopolista) e as Forças Armadas, mantendo um regime civil com tutela militar — sendo essa coparticipação uma característica do Estado brasileiro.

\section{Referências}

BORÓN, A. El fascismo como categoría histórica: en torno al problema de las dictaduras em América Latina. In: BORÓN, A. Estado, capitalismo y democracia en América Latina. Buenos Aires: CLACSO, 2003.

CUEVA, A. La fascistización del Estado em America Latina In: MARINI, R. M.; MILLÁN, M. La Teoría Social Latinoamericana: textos escogidos. Tomo III: A centralidade do marxismo. México: UNAM, 1995.

FIDELIS, T. A lei geral da acumulação capitalista e sua particularidade em condições de dependência latino-americana. In: NASCIMENTO, A.; FIDELIS, T.; NUNES, E. (org.) Economia, política e dependência: contribuições para a análise do Estado e da superexploração da força de trabalho no capitalismo dependente. Maceió, EDUFAL, 2020.

KONDER, L. Introdução ao fascismo. 2. ed. São Paulo: Expressão Popular, 2009.

MARINI, R. M. Dialéctica de la dependência. In: MARTINS, C. E. (org.). América Latina, dependencia y globalización. Bogotá: Siglo del Hombre - CLACSO, 2008. 
MARINI, R. M. El Estado de Contrainsurgencia. Cuardenos Políticos, México, n. 18, p. 21-29, out-dez. 1978.

PAXTON, R. O. Anatomia do fascismo. São Paulo: Paz e Terra, 2007.

SANTOS, T. Democracia e socialismo no capitalismo dependente. Petrópolis: Vozes, 1991.

TRAVERSO, E. The New Faces of Fascism: Populism and the Far Right. London, New York: Verso, 2019.

\section{Notas}

1 Isso implica no entendimento de que o fascismo não é um movimento morto, limitado à história da primeira metade do século XX na Europa e sem qualquer papel político contemporaneamente.

2 Segundo Konder, a ideologia racista na Alemanha fascista mostra com clareza o desdém aos valores humanos universais. Essa diminuição ou até a eliminação dos valores humanos foram fortalecidas, na Alemanha, pelo patriotismo fanático agressivo (chauvinismo).

3 Conforme Konder (2009, p. 43), as massas estavam "deficientemente preparadas no plano ideológico, deficientemente organizadas, inseguras e confusas, e submetidas a uma pressão que as desagregava internamente". Devido a isso tinham dificuldades em encontrar soluções coletivas e voltam-se às soluções individuais, abrindo o cerco para o fascismo.

4 É por isso que no Brasil as formas do Estado apresentam, em alguns momentos, feições fascistas sem poder caracterizá-lo como fascista. O Estado brasileiro, apesar de usar a retórica do nacionalismo e, por vezes, substituir os valores humanos pelo mito de nação, subjuga realmente a nação aos ditames do capital imperialista, fazendo com que o mito de nação se esvazie.

5 Nesse artigo a autora explica como a superexploração da força de trabalho compõe a estrutura dos países latino-americanos, sendo um dos pilares da acumulação capitalista dos países dependentes.

6 Esse processo difere do fascismo "histórico" que teve apoio massivo da pequena burguesia e de parcela do proletariado.

7 Diferente do fascismo clássico que era essencialmente antidemocrático.

8 Processo no qual as frações burguesas hegemônicas buscam recompor os mecanismos de acumulação de capital (CUEVA, 1995).

\section{Thays Karolline dos Santos Fidelis}

E-mail: thays.karoll@gmail.com

Mestre em Serviço Social pela Universidade Federal do Rio de Janeiro (UFRJ)

Doutoranda em Serviço Social pela Universidade Federal de Alagoas (UFAL)

\section{UFAL}

Av. Lourival Melo Mota, S/N, Tabuleiro do Martins

Maceió - AL - Brasil

CEP: 57072-900

\section{Raphael Lana Seabra}

E-mail: raphaelseabra@hotmail.com

Doutor em Sociologia pela Universidade de Brasília (UnB)

Professor Adjunto no Departamento de Estudos Latino-Americanos (ELA-UnB)

\section{Campus Universitário Darcy Ribeiro/UnB}

Prédio Multiuso II - Térreo e Primeiro Piso

Brasília - Distrito Federal - Brasil

CEP: 70910-900 


\section{Agradecimentos}

Não se aplica.

Agência financiadora

Não se aplica.

Contribuições dos autores

$\mathrm{O}$ artigo foi elaborado em todas as partes pelos autores.
Aprovação por Comitê de Ética e consentimento para participação

Não se aplica.

Consentimento para publicação

Consentimento dos autores.

Conflito de interesses

Não há conflito de interesses. 